\title{
ENTRE A VIDA E A RAZÃO: O FUNDAMENTO DA AÇÃO EM DEBATE
}

\author{
Robson Souza Rocha de Souza Júnior*
}

\section{INTRODUÇÃO}

O desenvolvimento de uma teoria da ação é uma das tarefas basilares das Ciências Sociais, sendo, inclusive, considerada por muitos de seus colaboradores como a tarefa fundamental destas ciências. Um de seus pais fundadores, Max Weber, compactua com essa idéia, o que o levaria à consideração do fundamento da ação nas primeiras páginas de seu clássico "Economia e Sociedade", na secção intitulada "Conceitos sociológicos fundamentais", onde intentaria estabelecer as características determinantes da ação, sobretudo da ação social que, segundo ele, seria para a Sociologia seu dado central e constitutivo (Weber, 2010 p. 44). De modo geral pode-se dizer que para Weber a ação é determinada pelo seu sentido, pela motivação que a orienta. Ainda que a ação possa receber várias motivações possíveis - tais como a tradição, o afeto e os valores, não obstante é a ação racional teleológica que serve como ponto de partida metodológico para a concepção weberiana da ação. É por isso que para Weber a ação racional referente a fins pode ser considerada o tipo-ideal de toda ação humana, o que significa que todo ato orientado por outras motivações tem de ser considerado um desvio deste tipo-ideal.

Contudo, independentemente das conseqüências dessa obra e da importância de Weber para a Sociologia, é evidente que esse não é o único modo de conceber a ação, o que Simmel nos demonstra numa gama de ensaios pouco conhecidos de sua obra que

\footnotetext{
*Mestre em Ciências Sociais pela Universidade Federal de Juiz de Fora (2012 - 2014) e Bacharel em Ciências Sociais pela Universidade Federal de Juiz de Fora (2006 - 2011). Contato: robson.rocha.jr@hotmail.com
} 
exploram, ainda que nem todos diretamente, o tema da ação. É bem verdade que, para Simmel, o desenvolvimento de uma teoria da ação não é a tarefa basilar da Sociologia. O conceito central de seu pensamento é o conceito de interação, ou ao pé da letra, o condicionamento recíproco [Wechselwirkung], através do qual Simmel pretende expressar o modo como concebe a práxis humana. Apesar disso, porém, a teoria da ação é um tema subjacente importante. Ocorre que aquele conceito central é circundado por um intricado complexo conceitual que ele mesmo articula. Deste complexo, é possível se destacar, além deste conceito central, dois aspectos determinantes, dentre os quais apenas um é importante de ser salientado aqui: o aspecto infra-estrutural da práxis, expresso em um dos dois étimos que compõem aquele conceito central já destacado: a Wirkung da Wechselwirkung; ou o condicionamento do condicionamento recíproco. Esse aspecto infra-estrutural expressa o caráter projetivo e produtivo da práxis, o móbile próprio da interação, já que toda interação supõe a ação dos indivíduos específicos enlaçados num contato interativo, o que significa que a ação individual é a condição infra-estrutural de possibilidade da práxis assim concebida.

Não obstante, essas duas formas de conceber a ação são frutos de um mesmo momento histórico - a modernidade -, ao qual buscam responder e corresponder através de propostas opostas. Essa condição aproxima as duas propostas de forma decisiva, o que buscaremos explorar ao longo deste artigo através da análise de três ensaios pouco conhecidos da obra de Simmel. No primeiro, intitulado "O conflito na cultura moderna" Simmel busca enquadrar a modernidade dentro do contexto global da história ocidental, acentuando seu posicionamento de ruptura em relação ao legado do Ocidente. Mas a modernidade não é um fenômeno unitário. Neste período da história ocidental duas perspectivas de mundo [Weltanschauungen] buscam se consolidar: convergentes em seu intento de re-interpretar o ser do homem e sua relação com o mundo, mas divergentes no que diz respeito aos seus princípios, formulações e desdobramentos fundamentais. É por isso que esse fenômeno histórico é tão importante para a compreensão das duas teorias da ação em debate, já que seus princípios basilares seriam estatuídos no decorrer deste processo de consolidação da modernidade como estado histórico vigente. 
Simmel se deterá de forma mais acurada ao significado dessas duas perspectivas de mundo no ensaio de nome "Kant e Goethe: a história das perspectivas de mundo moderna", onde nos são apresentadas as duas perspectivas de mundo da modernidade ocidental em seu status nascens: o racionalismo expresso pelo pensamento de Kant e o romantismo expresso pela obra de Goethe. Através da apresentação das distinções dessas duas perspectivas de mundo nascentes Simmel estabelece um empreendimento arqueológico, através do qual pretende apresentar a origem histórica de ambas as perspectivas de mundo, além de destacar seu posicionamento em relação à outra tradição vigente - que influenciaria a teoria da ação weberiana - e acentuar, além disso, através de um empreendimento genealógico a proeminência e a originariedade do fenômeno da vida, que está na base da perspectiva de mundo romântica, em relação à razão, que fundamenta a perspectiva de mundo racionalista.

Ocorre que, apesar de ambas as nascentes perspectivas de mundo serem fundamentalmente modernas e, portanto, compartilharem da orientação geral de ruptura que caracteriza a época moderna; por outro lado, buscaremos demonstrar que a perspectiva de mundo kantiana ainda preserva a proeminência da forma de vida sobre a própria vida, ao contrário da perspectiva de mundo de Goethe, que assume plenamente essa ruptura, intenção que se manifesta já na obra de Goethe, mas que só se consolidaria definitivamente através do pensamento de Schopenhauer e Nietzsche, filósofos que inauguram justamente o vitalismo na filosofia ocidental. Esta originariedade deverá ser evidenciada pela oposição mecanicismo/vitalismo. Enquanto a perspectiva racionalista de Kant tenha dado vazão à temporalidade que forma a base da experiência humana, ele ainda a concebe sob a égide da forma e é por isso, argumentará Simmel, que Kant concebe o tempo como um fenômeno mecânico. O contrário se verifica com a corrente vitalista, para a qual a temporalidade que marca a experiência humana se caracteriza justamente pela negação de toda forma, o que culminará numa recolocação do problema basilar da relação entre a vida e sua expressão numa forma.

Logo, ainda que a análise aqui empreendida vise retirar suas conclusões mais relevantes do confronto desses dois modelos de teoria da ação, é fundamental já 
destacar que a reflexão aqui ensaiada assume a posição de Simmel, pois sua proposta se apresenta como mais radical e mais originária do que a proposta weberiana, na medida em que ele assume expressamente a posição vitalista que, segundo nos parece, está mais afinada com a ruptura característica da modernidade e com suas consequências mais importantes. Pretendemos demonstrar essa maior radicalidade através da recorrência a outro sociólogo alemão importante: Alfred Schutz. Isso, porque, seu esforço em conjugar a análise fenomenológica, calcada na análise da ação e de seu significado como um fenômeno imediato que escapa ao controle do ator; com o princípio teleológico que forma a base da ação segundo a perspectiva weberiana, esta que concede o sentido da ação justamente ao controle que o ator almeja ao intentar um fim tem o mérito de demonstrar que esse controle do ator sobre sua ação é relativo e está em função do curso da vida do agente e das possibilidades que lhes são abertas em virtude desse mesmo percurso. Através dessa mediação pretende-se demonstrar, então, a originariedade da vida em relação à razão; isto é, a radicalidade da pulsão vital em relação á forma de expressão dessa mesma pulsão.

Este último tema - a originariedade da vida em relação à razão - deve ser aprofundado no terceiro ensaio-chave de Simmel a ser explorado, intitulado "O homem e sua vontade", onde Simmel busca confrontar aquelas duas visões de mundo e demonstrar que a tradição ocidental baseou sua interpretação da ação sustentando a proeminência da razão como traço característico do ser do homem, já que considerou a razão e o conhecimento como o centro da vida, o que fez com que a filosofia ocidental não tivesse nada a nos dizer acerca do conceito de fato, sobre a enigmática estrutura da experiência imediata e anterior à razão (Simmel, 1971, p. 235). Partindo de um diálogo com Schopenhauer, sobretudo da crítica empreendida por esse filósofo alemão ao racionalismo de Kant - tanto no âmbito epistemológico como no âmbito moral Simmel pretende demonstrar o mesmo que Schutz em suas análises sóciofenomenológicas; isto é, que o fim intentando por um agente nunca está totalmente sobre seu controle, constituindo, na verdade, uma função organicamente fundida à 
pulsão vital inesgotável e incontrolável que está no âmago da ação humana e que a impele o agente à ação quase que espontaneamente.

Desta feita, é evidente a possibilidade de um debate produtivo entre esses dois modos de conceber a ação. A contraposição oferecida por Simmel servirá de baliza para se estabelecer as diversas pontes e confrontações entre os princípios e seus desdobramentos mais importantes. A princípio ocupar-se-á no estabelecimento da base desse diálogo através de uma exegese das duas perspectivas de mundo, sobretudo, através da análise do ensaio "Kant e Goethe: a história das perspectivas de mundo moderna", onde Simmel expõe os princípios norteadores desses dois modos de conceber o homem e sua ação, além de explorar alguns desdobramentos importantes. Num segundo momento, deter-se-á numa análise mais acurada das duas teorias da ação, iniciando-se com a interpretação dos "Conceitos sociológicos fundamentais" de Weber e terminando com o ensaio de Simmel de nome "A transcendência da vida". Além disso, será importante, nesse momento, destacar a congruência daquelas duas perspectivas de mundo com as respectivas teorias da ação, acentuando a proximidade entre a perspectiva de mundo de Kant e a teoria da ação de Weber, de um lado, e a perspectiva de mundo de Goethe e a teoria da ação de Simmel, por outro. Valendo-se dessa base partir-se-á então para uma confrontação direta e crítica entre essas duas formas de conceber a ação, o que será erigido através da análise dos ensaios de Simmel intitulados "O conflito na cultura moderna" e "O homem e sua vontade" e do diálogo final com Alfred Schutz, cujas reflexões serão fulcrais para a hipótese proposta por esse artigo: a originariedade da vida em relação à razão como móbile da ação humana.

\section{A BASE ARQUEOLÓGICA E A FORMULAÇÃO DA TEORIA DA AÇÃO DE WEBER E SIMMEL}

O primeiro ponto a se destacar é que a oposição proposta por Simmel entre essas duas perspectivas de mundo modernas é fundamental para a construção do argumento intentado por esse artigo. A primeira suposição que será examinada é a de que aquelas 
duas teorias da ação que acentuamos - a de Weber e a do próprio Simmel - se assentam sobre os pilares dos dois princípios fundamentais dessas perspectivas de mundo. Somente após este passo nos parece possível uma confrontação crítica entre as duas propostas. Vejamos, então, como Simmel desenvolve essa oposição a partir da análise do ensaio "Kant e Goethe: história das perspectivas de mundo modernas".

Segundo Simmel, Kant nos demonstrou, sobretudo, que todo objeto de conhecimento só nos é acessível através de representações cognitivas, que são "reuniões [Vereinigungen] de impressões sensoriais" (Simmel, 1906, p. 4) conduzidas por processos subjetivos que as condicionam. Sendo assim, como a atividade de representação do ego forma o mundo, então as leis que governam nossa mente têm que ser as mesmas leis que governam o mundo fenomênico. Kant expressa essa idéia ao afirmar que a compreensão determina as leis em operação na natureza, o que quer dizer que a gama caótica de impressões sensoriais só se conformam a um sistema compreensível quando a capacidade de organização de nossa compreensão aloca essas impressões numa série estruturada.

Goethe, por seu lado, "combina esses elementos de forma totalmente diferente e alcança, ainda assim, uma unificação igualmente válida" (Simmel, 1906, p. 7). Para ele o contato do homem com o mundo não pode ser mediado por algo como uma representação cognitiva forjada sob os moldes da subjetividade, pois o homem está em contato direto com o mundo (Simmel, 1906, p. 7). Por isso, para Goethe, o modo como Kant propõe a relação do homem com o mundo é inaceitável. Para ele é impossível descer abaixo da aparência e através disso defini-la como uma mera representação de um ego que encapsula essa experiência imediata através de funções cognitivas que dão forma a essas representações. Na verdade, natureza e espírito se reconciliam já no nível da aparência que é a autêntica verdade e o único nível concebível, formando uma unidade onde se conciliam o real e o ideal, tendo em vista "a espiritualidade da natureza e a naturalidade do espírito" (Simmel, 1906, p. 9). Isso significa que o princípio da vida, que é aparente na natureza, também vale para a alma humana, já que ambos emergem 
da unidade do ser uno e, por isso, possuem a mesma validade, como expressões legítimas deste mesmo princípio.

Pode-se precisar mais claramente a distinção entre as duas perspectivas de mundo ao se apontar para o princípio fundamental sobre o qual se sustentam. As duas perspectivas de mundo partem, na verdade, de princípios opostos: enquanto Kant se baseia no princípio da demarcação [Grenzsetzung], Goethe baseia sua reflexão no princípio da unidade [Einheit] (Simmel, 1906, p. 25). A oposição basilar entre estes dois princípios-guia determina a diferença radical entre essas duas formas de conceber o homem e sua relação com o mundo. Por isso, segundo Kant, baseado no princípio da demarcação, o centro do espírito subjetivo forma o coração da natureza, já que, como o espírito está presente em todo lugar, então até mesmo a natureza tem de estar fundamentada por ele. Já para Goethe, impelido pelo princípio da unidade, tanto a natureza como o espírito são expressões do mesmo ser divino, que envolve a natureza na dimensão externa com a mesma realidade que está presente no interior da alma, dimensão interna desse ser divino.

Essa diferença se torna ainda mais patente quando se atenta para o modo como ambos concebem a relação desses princípios-guia com a consciência individual; a relação entre o modo como concebem o ser e a consciência. Como para Kant a razão determina as leis gerais da natureza, então deve haver uma clara demarcação entre sujeito e objeto; demarcação que Goethe rejeita veementemente, já que, para ele, essa relação expressa um processo unitário que se apresenta a si mesmo, segundo a perspectiva do ser unitário, como o desenvolvimento de sua própria trajetória até o estado mental, e, sob a ótica da consciência, como a apropriação cognitiva da natureza.

Isso tudo demonstra que, por estarem baseadas em princípios-guia opostos, essas duas perspectivas de mundo tem de se contrapor de modo decisivo e insolúvel. Não há ponte possível entre esses dois modos de conceber o mundo e o homem, o que ficará ainda mais claro quando estiverem evidentes os reflexos dessa oposição na definição de ambos acerca do Self, da individualidade dos atores humanos. É neste ponto, inclusive, 
que estatuiremos a ponte para o próximo passo fundamental desse empreendimento que visa demonstrar o paralelo entre os dois princípios-guia dessas duas perspectivas de mundo e as duas teorias da ação em debate. Sobre o fundamento do princípio da demarcação Kant nos legaria uma interpretação do Self humano que perfaz sua definição da individualidade e se apresenta como ponto nodal da teoria da ação weberiana. Já Goethe, baseado no princípio da unidade, nos fornece uma interpretação distinta desse mesmo Self, o que influencia decisivamente a formulação simmeliana acerca da ação. Isso é o que buscaremos demonstrar a partir de agora. Nesse momento saímos, então, da esfera da análise meramente metafísica da constituição do homem e do mundo, para nos voltarmos para as consequências éticas de cada uma dessas perspectivas de mundo. Estamos já a caminho da apresentação e confrontação de ambas as teorias da ação.

Como nos demonstra Simmel, para Kant o valor moral está localizado em um terreno essencialmente distinto de qualquer outro modo de existência e seu sentido. A ética kantiana está baseada em uma diferença de valor fundamental e irreconciliável entre os sentidos e a razão o que evidencia já os reflexos do princípio da demarcação que está na base da perspectiva de mundo mecanicista. $\mathrm{O}$ valor absoluto estaria, então, fundamentado no reino da razão, que é a ordem transcendental da qual fazemos parte apenas parcialmente. Apesar de parcial, é justamente esse pertencimento que confere valor e dignidade própria e inalienável ao indivíduo humano, na medida em que cada indivíduo, ao estar essencialmente referido a essa ordem, possui fim em si mesmo. É esse valor intrínseco que encerra o indivíduo em si mesmo e lhe confere a dignidade incorruptível que o caracteriza, independente de qualquer de suas realizações e atividades pessoais. Segundo Kant, essa dignidade é algo que faz parte da íntima essência do ser humano racional, ele que já está "destinado por sua própria natureza como fim em si mesmo, [...] como ser livre em relação a todas as leis da natureza" (Kant, 2009, p. 269).

Percebe-se, então, que a moralidade está situada num nível totalmente próprio, no nível transcendental, que só pode ser acessado a partir da esfera da vida diária 
quando o indivíduo, agindo moralmente, abandona todos os impulsos empíricosensoriais e age com autonomia, impondo a si mesmo a máxima ética que o impele a agir de acordo com a dignidade intrínseca ao seu próprio. É por isso que, para Kant, a moral pessoal representa o propósito mais elevado no mundo, valendo como a sede do valor absoluto, o que, no fundo, significa que a liberdade é a mesma para todos os seres racionais, na medida em que todos eles possuem a vontade livre, mesmo quando não agem de acordo com essa liberdade. Todo indivíduo singular pertence de maneira equânime a esse reino inteligível o que confere a cada um deles a dignidade de sua vontade, que se caracteriza, sobretudo, pela autonomia, pela possibilidade de conduzir sua própria vontade através das leis universais da espontaneidade pura da razão que impõe ao ato individual um critério geral e abstrato que vale para todo indivíduo de modo igual. Essa submissão da ação individual a uma norma supra-individual e anônima (a razão) que é válida para o "homem em geral" forma a base da noção kantiana da individualidade, esta que pode ser definida como a expressão singular de uma lei universal. A autonomia da vontade é a principal característica do indivíduo assim concebido, claramente marcado pela liberdade de pôr fins a si mesmo de modo racional.

Para Goethe, por outro lado, o valor moral não está ligado a uma esfera inteligível apartada do mundo empírico, mas sim vinculado a todos os outros elementos da vida em uma série única e continuamente ascendente, o que aponta para a assunção do princípio da unidade, basilar para a perspectiva de mundo romântica, também na esfera moral. Por isso, enquanto na ética kantiana há uma diferença de valor fundamental e irreconciliável entre os sentidos e a razão; para Goethe, a unidade metafísica de todos os elementos da vida tem de ser transmitida também para o valor moral. Ocorre que, para Goethe a natureza é o lócus onde se desenvolve o espírito humano. Por outro lado, a natureza alcança seu fim mais elevado na objetivação espiritual e, por isso, carece também do homem. Por isso, a exigência ética segundo esse princípio determina que todos os seres humanos desenvolvam de forma tão completa e clara quanto seja possível toda aquela natureza que lhes fora aplicada, de tal 


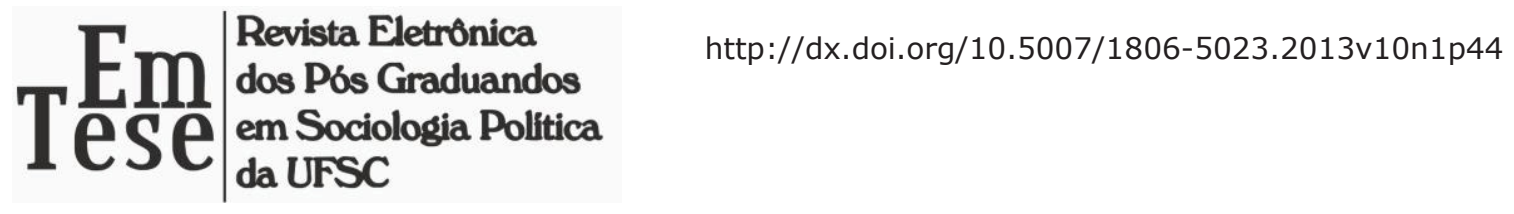

maneira que cada um possa alcançar o máximo desenvolvimento de sua forma pessoal irreproduzível, o que será possível na medida em que cada um realize de maneira própria e distinta suas potencialidades naturais. Sua exigência mais fundamental é, portanto, desenvolver todos os seus talentos ao se valer ao máximo do uso dos recursos disponíveis, com o fim de permitir à natureza chegar, dentro de si, à sua mais completa expressão.

Sendo assim, em síntese pode-se dizer que para Kant a natureza só adquire valor através do ser humano. Já para Goethe, por outro lado, é a Natureza que mobiliza o ser humano, este que ocupa uma posição de eminência simplesmente porque a Natureza se desenvolveu em seu mais alto grau através de seu ser, alcançando assim seu mais alto ponto de criação.

Definido o modo como a individualidade é concebida segundo os moldes das duas perspectivas de mundo apresentadas, pode-se agora averiguar o modo como a teoria da ação de Weber e a teoria da ação de Simmel se erguem a partir dessa definição da individualidade. Será importante notar a congruência entre essas duas definições da individualidade e as duas teorias da ação em debate, o que será possível caso se demonstre que os princípios que regem as duas perspectivas de mundo em questão também valem para as duas referidas teorias da ação, justificando, inclusive, a assunção dessas noções de individualidade, respectivamente por Weber e Simmel. Iniciemos com uma apresentação das duas teorias da ação.

Weber se serve do pressuposto de uma razão universal como fundamento último da ação real. Por isso, para ele, o que de fato fundamenta uma ação não é sua gênese, mas sim o sentido intentado pelo agente, sua motivação, o que nada mais é do que uma conexão de sentido que surge do próprio agente como fundamento significativo de um comportamento. Isso significa que o decurso típico da ação baseia-se em nexos de sentido compreensíveis que se tornam inteligíveis para o agente através da compreensão atual do fim intentado em uma ação. 
Contudo, na teoria weberiana, o conceito de racionalidade é consideravelmente complexo, na medida em que conjuga uma série de significados correlacionados que se unificam segundo a idéia de uma racionalidade prática. São três os tipos de racionalidade subjacentes. Primeiramente, destaca-se a racionalidade instrumental, que forma a base de seu conceito de racionalidade, e que pode ser definida, por um lado, pelo emprego regulado de meios que podem ser mais ou menos racionais em referência a um fim almejado; além de ter, por outro lado, a eficácia como critério de avaliação dos meios utilizados em vistas a um fim determinado. O segundo tipo de racionalidade subjacente é a racionalidade eletiva. Ela pode ser definida como a racionalidade de eleger fins mais racionais, já que não só os meios empregados podem ser medidos quanto a sua racionalidade - o que define a razão instrumental -, como também os fins eleitos pelo ator podem ser mais ou menos racionais. Essas duas primeiras definições da racionalidade estão inscritas na ideia de uma motivação puramente teleológico-racional da ação e representam o conceito-chave da concepção de racionalidade prática na teoria weberiana, que seria complementada pela ideia de uma racionalidade normativa, motivação que guia a ação segundo máximas que dão forma a uma vida regida por princípios com validade universal para quem os emprega.

Ora, como a ação teleológico-racional forma o centro típico-ideal em torno do qual gravita a ação real, então, por um lado, os motivos estritamente racionais são inteiramente compreensíveis, valendo como o decurso tipicamente observado da ação humana e, por outro, todas as outras orientações são irracionalidades, o que vale até mesmo para ação racional axiológica. Por isso, para Weber, apenas a relação entre o meio e o fim é unívoca, o que significa que, quando se age de um "modo estritamente racional e teleológico, se teve de atuar assim e não de outro modo" (Weber, 2010, p. 33), já que essa é a natureza típica do ser humano.

Apesar disso, a fronteira entre uma ação significativa e uma conduta meramente reativa que não está ligada a um sentido é de todo fluída, já que os elementos compreensíveis e não compreensíveis estão mesclados e conexos na ação. Logo, por mais que a ação teleológica mantenha-se como base da investigação do sentido da ação, 
não obstante, ela pode receber interferência de outras motivações que fogem a esse padrão e, portanto, são irracionais: tais como as motivações afetivas e/ou baseadas em um hábito tradicional. Por isso, para se determinar o decurso de uma ação real é necessário, em primeiro lugar, considerar como ela se desenvolveria sem a influência dessas motivações irracionais para, em seguida, considerar como esses componentes irracionais interferem em seu decurso típico.

Além disso, destaca-se também o fato de que a ação, que possui uma orientação significativamente compreensível, só é possível como ação de um ou de vários indivíduos singulares, o que significa que cada qual elege a motivação que lhe convém como fundamento de sua ação e age de modo plenamente individual. Por isso, mesmo as formações coletivas são nada mais do que "o entrosamento do agir específico de homens singulares" (Weber, 2010, p. 24), já que somente eles são capazes de orientar sua ação segundo um sentido compreensível. Outrossim, como a ação, para Weber, está sob o controle do indivíduo que define as metas que orientam o seu agir e elege os meios apropriados para a sua consecução, então, deve estar também sob o seu controle a possibilidade de orientar ou não sua ação pelo comportamento dos outros agentes. É por isso que, para Weber, nem toda ação é uma ação social, já que apenas o comportamento próprio orientado, quanto ao sentido, pelo comportamento de outros pode ser considerado uma ação social. Pelos mesmos motivos nem toda ação social pode ser considerada uma relação social, uma vez que a relação social se refere a um comportamento de vários indivíduos que apresentam um conteúdo de sentido reciprocamente referido, o que quer dizer que apenas quando um determinado fim é compartilhado intencionalmente pelos agentes é que há de fato uma relação social.

Já para Simmel toda ação individual tem como base uma força pulsante inesgotável: a vida. Este aspecto determinante da ação Simmel denomina de Mais-vida [Mehr-Leben], conceito que pretende expressar o incessante processo que "é" a vida, "o processo contínuo de se lançar por sobre si mesma [Sich-über-sich-selbst-Erhebens]" (Simmel, 1922, p. 16), cuja essência irredutível, baseada em sua temporalidade inerente, é fluir e exceder qualquer determinação. A temporalidade da vida é, portanto, o 
fundamento da ação. Ela condiciona o indivíduo de tal forma que lhe é aberta apenas a possibilidade de dar forma a esta determinação através da formação de uma individualidade típica. Olli Pyyhtinen define bem está força como um "fluxo préindividual" (Pyyhtinnen, 2010, p. 55), uma força que "é" a própria vida, que por ser essencialmente temporal, na verdade "nunca é, mas sim sempre está se tornando [becoming]" (Pyyhtinnen, 2010 p. 55). Essa força "não só excede, mas também produz todas as formas individuais." (Pyyhtinnen, 2010, p. 55). Por isso, ainda que, de fato, a personalidade individual conceda limites e forma a este fluxo incessante, não obstante, ainda assim a vida não cessa de seguir seu curso ininterrupto, já que esta é sua característica fundamental e o homem é apenas o ator desta pulsão em curso inesgotável.

Por outro lado, porém, a vida é também Mais-do-que-vida [Mehr-als-Leben], conceito que expressa a forma própria e irreproduzível de cada individualidade, "o serpra-si [Fürsichsein] e o ser-em-si [Insichsein] da forma individual em seu contraste em relação à corrente contínua da vida" (Simmel, 1922, p. 18). Apesar de conceder a forma através da qual a vida poderá se expressar, não obstante, essa forma não é capaz de interromper ou cessar o fluxo incessante que "é" a vida. É por isso que, na verdade, ator e ação se confundem, pois o sujeito é a própria atuação do fluxo inesgotável da vida em uma forma própria e particular, o que nos permite caracterizar a ação como uma força atuante e a individualidade como a forma própria dessa força. Ninguém melhor do que Nietzsche em a Genealogia da Moral expressa essa ideia ao nos dizer que "não existe 'ser' por traz do fazer, do atuar, do devir: 'o agente' é uma ficção acrescentada à ação a ação é tudo." (Nietzsche, 1988, p. 43).

Além disso, essa forma individual, para Simmel, teria um duplo significado. De um lado ela representa "o senso de liberdade e responsabilidade por si mesmo" (Simmel, 1971, p. 271), significado incluso na propriedade [Eigenheit] de cada individualidade, que representa o peso da assunção da existência individual. De outro, ela expressa a idéia de que "um ser humano singular que se distingue a si mesmo dos demais" (Simmel, 1971, p. 271), o que aponta para aquela particularidade 
idiossincrática de cada forma individual, a irreprodutível [Einzigkeit] diferenciação desta forma individual - de seu espírito subjetivo - em relação aos demais indivíduos. Sendo assim, como o que caracteriza decisivamente cada individualidade é sua forma própria e irreproduzível, então esta maneira de conceber a ação está baseada na distinção e desigualdade inerente entre as individualidades. Fundamental é notar que seu valor não é conferido pelo valor genérico da razão, mas sim pela idiossincrasia absoluta de uma forma individual absolutamente particular. Segundo esta perspectiva, "Cada pessoa é conclamada a realizar seu próprio, ou melhor, seu mais próprio protótipo" (Simmel, 1971, p. 224), de assumir com propriedade a tarefa de formar uma individualidade própria e irreproduzível, o que só é possível na medida em que "cada indivíduo encontre o sentido de sua vida na sua diferença em relação a todos os outros, na unicidade pessoal de sua natureza e de sua atividade." (Simmel, 1971, p. 224) e se torne apto a servir aos fins da vida de se objetivar como espírito e alcançar seu télos mais elevado.

Posto isso, pode-se, enfim, traçar alguns comentários acerca da vinculação daquelas duas perspectivas de mundo com as duas teorias da ação apresentadas. Primeiramente, acentua-se o fato de que Weber concebe a individualidade como a expressão singular de uma universalidade (a razão), já que ele considera que só é possível conceber a ação de homens singulares, estes que são os únicos seres capazes de operar o padrão universal da ação, os únicos portadores compreensíveis de um agir orientado segundo o sentido, o que cada um realiza ao intentar um fim específico e mobilizar os meios apropriados para a sua consecução. É por isso também que toda influência que não provenha da racionalidade teleológica é considerada por Weber um desvio ou perturbação daquele decurso natural, tipicamente racional, da ação humana. Como se nota, esta definição da individualidade o aproxima decisivamente da noção de individualidade forjada sob os moldes da perspectiva de mundo racionalista, fato que fica ainda mais evidente quando Weber afirma basear sua interpretação da ação no ponto de vista do agir teleológico racional, por ser a única motivação da ação que possui inteligibilidade evidente e univocidade afixa à racionalidade que ocupa o centro da 


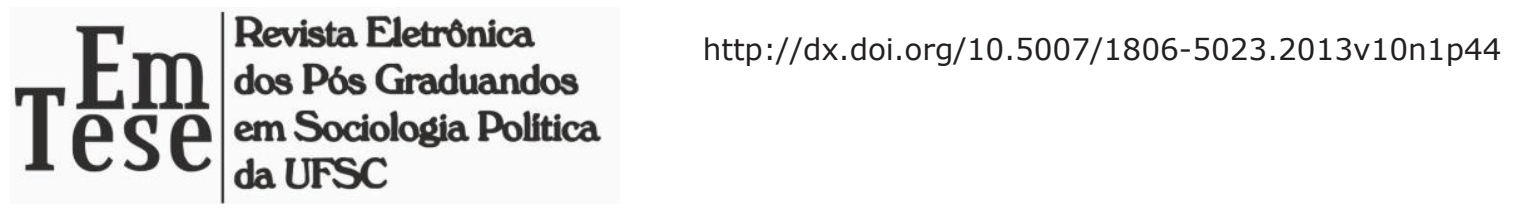

estrutura significativa que orienta a ação. Simmel sustenta o contrário, já que acentua, assim como Goethe, a idiossincrasia absoluta das individualidades que podem assumir de maneira variada a força vital pulsante que fundamenta a ação e dá vida a uma forma variada de manifestações vitais: os próprios indivíduos. Nenhum fim intentado pelo ator pode definir sua ação, pois cada fim específico é apenas um momento de um todo indiviso formado pela individualidade radicalmente particular de cada ator, esta última que é continuamente mobilizada pela força pulsante da vida que é inesgotável e não se exaure em nenhum fim particular intentado. Além disso, destaca-se também o fato de que ambas as teorias da ação se valem do conceito central das duas perspectivas de mundo analisadas para erigirem sua formulação do significado da ação. Enquanto para Weber a racionalidade é o paradigma básico da ação, para Simmel é a vida que forma sua base fundamental, o que revela um perfeito paralelo entre as duas perspectivas de mundo e as duas teorias da ação em destaque.

\section{A VIDA EM RELAÇÃO À RAZÃO}

As duas tentativas de re-interpretação do ser do homem e de sua relação com o mundo - as coisas e os outros homens - expressas por aquelas duas perspectivas de mundo, nada mais são do que respostas distintas a um momento histórico decisivo, a modernidade, momento em que - como acentua Simmel em "O conflito na cultura moderna" - o predomínio da forma racional historicamente constituída no Ocidente entraria em colapso e a vida emergiria como fenômeno originário de forma tão avassaladora que poria em xeque o predomínio - assumido na tradição ocidental desde a Grécia antiga - da forma vital sobre o processo vital, o que levaria toda uma tradição milenar a um processo de dissolução.

De acordo com Simmel "uma contradição interna se expressa no desenvolvimento da vida desde o nível animal passando pelo nível espiritual até o nível cultural." (Simmel, 1971, p. 375). Na verdade, toda a história da cultura é o processamento dessa contradição, o que pode ser expresso da seguinte maneira. A vida 
produz certas formas nas quais ela se expressa e se realiza. Essas formas representam uma expressão completamente adequada da vida imediata, que vale, por isso, quase que como uma pele organicamente fundida à vida. Deste prisma, a forma da vida não é nada além de sua expressão. Apesar disso, essas formas, que são estruturas que servem à vida criativa, não compartilham do inquieto ritmo da vida que mantém a contínua pulsão de produzir e transcender essas formas que ela mesma produz para se manifestar e por isso estão em constante oposição a este processo vital que as alimenta e que as produziu.

Frente a isso fica claro o posicionamento decisivo e radical da modernidade dentro da história ocidental. A peculiaridade profunda desta nova forma de embate vital, tanto no que se refere à sua extensão como à sua intensidade, reside no fato de que este embate já não se concentra mais na criação de novas formas, na medida em que nessa época "a vida combate contra a forma como tal, contra o princípio da forma" (Simmel, 1971, p. 376). Por isso, "visto a partir da perspectiva cultural mais geral, este movimento no seio da modernidade implica numa ruptura em relação ao classicismo como ideal absoluto da cultura humana [...], já que o classicismo é a ideologia da forma, esta que é considerada a norma suprema para a vida e a criação" (Simmel, 1971, p. $388)$.

Os sistemas fechados do classicismo visam unir todas as verdades em seus conceitos mais gerais, dentro de uma estrutura de elementos arranjado sistematicamente e desdobrado em todas as direções. Isso representa a mais extrema culminação do princípio da forma: perfeição da forma como critério supremo de verdade. É contra essa perspectiva que a modernidade se volta de forma decisiva. Por isso, apesar de sua natureza essencialmente negativa, essa época assumiria a tarefa decisiva de reformular o modo de expressão da vida, exercício que seria conduzido por aquelas duas correntes de pensamento que estatuiriam as duas perspectivas de mundo características da modernidade. Uma dessas correntes está vinculada à tradição ocidental que privilegia a forma, apesar de já dar vazão à necessidade da vida de se sobrepujar em relação às suas formas. Ela forma a base da perspectiva de mundo mecanicista impetrada por Kant e que culminaria na teoria da ação weberiana. A outra corrente - responsável pela 
perspectiva de mundo romântica e vitalista - se expressará como teoria da ação a partir da reflexão simmeliana e está mais afinada com a pulsão de ruptura da modernidade em relação à tradição ocidental, com aquela necessidade do fluxo vital de se livrar de suas formas obsoletas e refratárias. Por isso, a oposição entre essas duas perspectivas de mundo é tão fundamental para o pensamento de Simmel, porque ela expressa de forma paradigmática esse momento limítrofe de ruptura, na medida em que aponta tanto para a pulsão que vincula a modernidade à tradição ocidental, como para a pulsão à ruptura radical. É nesse ponto que se pode medir a originariedade de uma proposta em relação à outra, o que será evidenciado pela análise do ensaio "O homem e sua vontade", onde Simmel aborda, a partir de um diálogo com Schopenhauer, o primado da vontade vital inesgotável em relação à limitada consciência racional.

O ponto de partida de Schopenhauer é, segundo Simmel, a perspectiva de mundo kantiana que está baseada naquela separação absoluta entre o fenômeno e a coisa-em-si. A tese central da teoria kantiana destaca o fato de que a sede da realidade se aloca na fenomenalidade. Sua conclusão versa que o mundo é fenômeno e por isso é plenamente objetivo, real e penetrável até o fundo, o que indica que tudo que vai além desta esfera não seria mais do que uma fantasia sem conteúdo. Mas Schopenhauer saca deste axioma da fenomenalidade justamente a consequência contrária. Para ele o mundo é algo relativo, o que quer dizer que precisa estar fundamentado por algo absoluto (Simmel, 1963, p. 19). Enquanto para Kant, a realidade é uma categoria formadora de experiência, o que o levou a não ultrapassar a fenomenalidade da existência; já para Schopenhauer, por ansiar o metafísico absoluto, é justamente o contrário de toda a experiência que fundamenta a própria experiência, de forma que para se acessar esse absoluto, esta fenomenalidade deve ser convertida em simples meio utilizado para sinalizar essa realidade metafísica (Simmel, 1963, p. 21). Contudo, o que interessa Schopenhauer não é tanto a demarcação entre essas duas esferas, mas sim o elo que une esse incondicionado que fundamenta a fenomenalidade e a própria fenomenalidade em uma unidade. 
O homem é esse ser limítrofe, que vive no limite e na decisão dessas duas esferas, o que indica que a metafísica de Schopenhauer está baseada, então, na posição limítrofe ocupada pelo sujeito, alocado entre a fenomenalidade do mundo e a coisa-emsi. Posto que a vontade seja essa coisa-em-si e o homem ocupe essa posição intermediária entre essa mesma coisa-em-si e os fenômenos; então, não deve estranhar o fato de que exteriormente toda ação pareça ser impetrada pelo próprio sujeito, enquanto, na verdade, visto por dentro é nada mais do que uma ação da vontade, uma vez que ação e vontade representam, respectivamente, "o aspecto exterior e o aspecto interior de uma mesma realidade" (Simmel, 1963, p. 24), o que, diga-se de passagem, está muito próximo daquilo que Goethe e Simmel pensam acerca da ação.

É neste ponto que alcançamos o momento decisivo deste artigo. O modo como Schopenahuer se coloca frente a Kant se aproxima muito da oposição que averiguamos entre Goethe e Kant, mas o mais importante é a crítica que Schopenhauer nos oferece da teoria kantiana a partir dessa base. Simmel aborda essa crítica acentuando os dois significados básicos da metafísica de Schopenhauer. Antes de tudo se destaca o fato de que o absoluto para Schopenhauer não é algo substancial, mas sim o contínuo e inesgotável fluxo da vontade vital, “a inesgotabilidade do nosso ser total, a continuação ininterrupta que ultrapassa todo ato particular, o mais que isso que sempre está próximo e além de todas as nossas manifestações particulares”. (Simmel, 1963, pp. 27, 28). Isso que sentimos como a inesgotabilidade de nosso ser e, ao mesmo tempo, como o que está para além de todas as nossas manifestações particulares; pode ser representado por uma encadeação lógica infinita, que se realiza na unidade da alma que se constitui a partir das relações mútuas de seus atos particulares, mas que nunca se realiza plenamente.

Além disso, essa tese da inesgotabilidade da vontade permite a Schopenhauer uma percepção profunda que resume o intento desse artigo. Como nos aponta Simmel, para toda a filosofia anterior o homem era concebido como um ser de razão. Não que fosse desconsiderado a gama considerável de irracionalidades que também o caracterizam. Mas essas suas características irracionais eram concebidas apenas como desvios de sua natureza própria, daquilo que ele deve ser e já o é, na medida em que 
essa sua natureza se lhe impõe não só como idéia e aspiração moral, mas também como sua realidade mais profunda. Segundo Simmel, portanto, o grande feito de Schopenhauer reside no fato de ter "destroçado o dogma que sustenta que a razão constitui o mais profundo fundamento do homem" (Simmel, 1963, p. 29) e estabelecer uma guinada atrevida que transforma a razão em um acidente, um meio ou, enfim, uma conseqüência da vontade, que demanda para si essa consciência para se manifestar, como uma função vital. O principal é notar que essa construção implica no fato de que mesmo as representações e os encadeamentos do entendimento pressupõem, na medida em que são processos vitais, uma força impulsiva que vive além ou aquém das relações meramente intelectuais e lógicas. O que está implicado nessa conclusão é justamente aquela originariedade da vida em relação à razão. Afirmar que as representações cognitivas são "processos vitais" é o mesmo que definir que a razão e todas as operações que a caracterizam estão em função da vida que a produziu, ou melhor, da forma de vida que lhe é subjacente. Isso significa que a vontade estaria apartada tanto da razão como de seu contrário, a irracionalidade, por se tratar de uma realidade mais originária que antecede e fundamenta os processos cognitivos e racionais. Isso também quer dizer que não há um conceito unívoco de racionalidade, como Weber pretendera definir. Na realidade, o que há são formas diversas de racionalidade, cada qual orientada por uma forma de vida específica e orientada para modos distintos de articulação entre o que o agente almeje e o que lhe é aberto como possibilidade por sua trajetória de vida e pelo contexto vital em que está inserido.

$\mathrm{Na}$ realidade, talvez seja possível considerar que, apesar de um dos dois pólos prevalecer em relação ao outro, tanto a perspectiva que concebe o homem como o promovedor e executor de fins, como aquela que o concebe como um móbile da vontade espontânea, de uma temporalidade que o impulsiona a agir e a eleger fins que promovam esse impulso inerente à realização da vida; provavelmente é possível perceber uma articulação dessas duas esferas na ação humana. No entanto, deverá estar claro que a racionalidade implicada na seleção dos fins está sempre em função do modo 
como a vida é assumida por cada ator em cada contexto vital específico. As análises de Alfred Schutz devem tornar essa articulação mais evidente.

Apesar de conhecer e estimar a obra de Simmel, o intento de Schutz é, na verdade, convergir a teoria da ação weberiana à fenomenologia, esta última que bebe na mesma fonte que Simmel e que, por isso, apostaria também numa concepção mais unitária da relação do homem - a consciência intencional - com o mundo - o objeto intencionado. Essa intersecção permitirá a Schutz desenvolver o conceito de "motivo" ou "fim" da ação de uma maneira sugestiva e esclarecedora.

Segundo Schutz o conceito de fim é considerado unívoco, quando, na verdade, ele possui dois significados distintos e articulados: ele "diz respeito a dois diferentes conjuntos de conceitos que devem ser distinguidos." (Schutz, 2012, p. 140) Primeiramente, motivo indica o fim que a ação deveria promover e, por isso, está apontado para o futuro. "Vamos chamar esse tipo de motivo de 'motivo-com-afinalidade-de" (Schutz, 2012, p. 140). Ao intentar esse fim o sujeito projeta no futuro o estado de coisas a ser realizado e passa, então, a tentar concretizar esse intento. Mas, em contraposição a esse significado do motivo, há também a idéia de um motivo "porque", que se refere às experiências passadas que o indivíduo vivenciou que foram decisivas para as escolhas dos motivos-com-a-finalidade-de que ele intentaria. Essa motivação se refere à "história de vida sedimenta em suas circunstâncias pessoais" (Schutz, 2012, p. 141) que determinam, condicionam ou ao menos restringem os projetos possíveis de um ator, já que "Essas experiências determinaram-no a agir do modo que agiu." (Schutz, 2012, p. 141).

Ora, o que essa formulação nos aponta é que o fim intentado por um ato está inscrito numa rede temporal que o alimenta e que restringe suas escolhas. Essa linha temporal articulada com os fins elegidos pelo ator forma uma série de atos que só têm sentido caso considerados em sua relação mútua, uma vez que todo motivo-com-afinalidade-de é condicionado pelo motivo-porque da ação, enquanto que o motivoporque da ação também foi promovido, anteriormente, por outro motivo-com-a- 


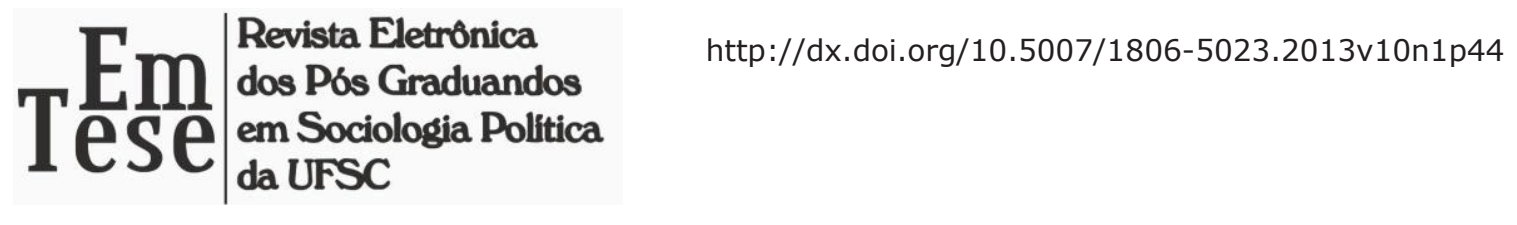

finalidade-de promovido e levado a efeito pelo ator num momento passado. Isso significa que a ação está, ao mesmo tempo, sob controle do indivíduo que elege os fins que guiam sua ação e fora de seu controle, pois o fim intentado por sua ação está inscrito numa linha temporal que segue de modo inexorável e que liga o fim intentado tanto ao passado do agente, como à sua projeção no futuro indeterminado.

\section{CONCLUSÃO}

Podemos, enfim, ensaiar uma conclusão através de uma confrontação final a partir do conceito fulcral de "fim" ou "motivo" da ação. Nesse ponto, segundo nos parece, a diferença se evidenciará em toda a sua amplitude e radicalidade. Concebido como ser de razão, o homem elege seus valores e fins e só então passa a desejá-los. Desta feita, o fim que é posto e valorado pela razão determina a apetência da vontade. A ação humana para Weber recebe esse tom. Já o homem concebido como expressão da vida estima o fim que a própria vida carece e que nasce espontaneamente da vontade como fato originário, o que quer dizer que não queremos porque nossa razão estabelece fins e valores, mas sim porque queremos continuamente, sem propósito, desde o mais fundo de nosso ser, pois mesmo os fins intentados racionalmente não são nada além do que a expressão ou a organização lógica dos processos espontâneos da vontade. Simmel é o defensor dessa interpretação da ação.

Como fora demonstrado no decorrer do texto, ambos os modos de conceber a ação são frutos da modernidade e de sua ruptura com o legado ocidental que privilegia a forma. É bem verdade que o mecanicismo kantiano, que forma a base da teoria da ação weberiana, ainda está demasiadamente vinculado a essa mesma tradição que almeja transcender, o que se manifesta em algumas de suas conclusões, sobretudo na confiança que deposita no controle do agente sobre sua ação, o que está manifesto no modo como concebe o 'fim' intentado pelos agentes. No entanto, caso se destaque a originariedade 


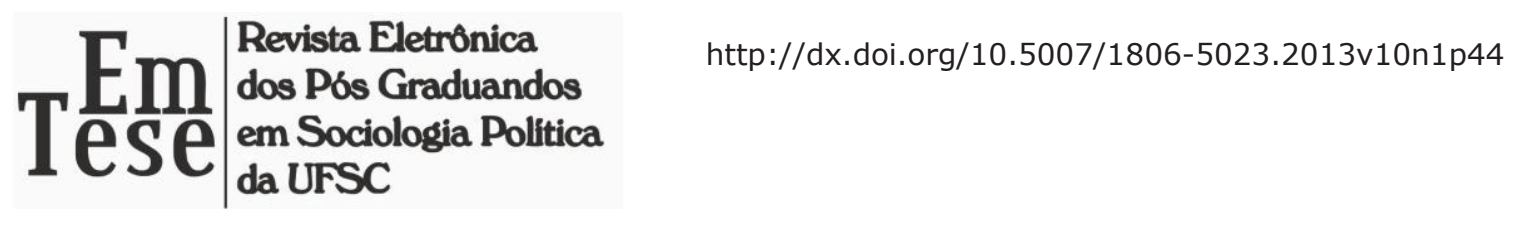

da proposta vitalista, o que implica em reconhecer que não há um conceito unívoco de racionalidade e, portanto, todo fim intentado por um agente está sempre parcialmente sob seu controle; então não é necessário descartar as reflexões weberianas. Melhor seria recolocá-la sob a ótica vitalista, demonstrando assim, que todo fim intentado por um agente está em função de seu contexto vital e do percurso da vida do ator nesse mesmo contexto. Sendo assim, a diferença, talvez, seja apenas de visada. Enquanto alguns autores preferirão destacar o controle do indivíduo sobre sua ação, outros destacarão a espontaneidade do ato que se desenvolve naturalmente de acordo com a estrutural temporal imanente à ação.

\section{REFERÊNCIAS}

KANT, Immanuel. Fundamentação da metafísica dos costumes. Barcarolla: São Paulo, 2009.

NIETZSCHE, Friedrich. A genealogia da moral. Editora Brasiliense: São Paulo, 1988.

PYYHTINNEN, Olli. Simmel and 'the social'. Palgrave and Macmilan: London, 2010.

SCHUTZ, Alfred. Sobre fenomenologia e relações sociais. Editora Vozes: Petrópolis, 2012.

SIMMEL, Georg. Kant und Goethe: die Geschichte den modernen Weltanschauungen. Bard Marquardt: Berlin, 1906.

. Lebensanschauung: vier metaphysische Kapitel. Verlag von Duncker \& Humblot: Berlin und Leipzig, 1922.

$\overline{\text { Chicago, } 1971 .}$

On individuality and social forms. University of Chicago Press:

. Schopenhauer y Nietzsche. Francisco Beltrán: Madrid, 1963.

WEBER, Max. Conceitos sociológicos fundamentais. Lusofonia: Covilhã, 2010. 


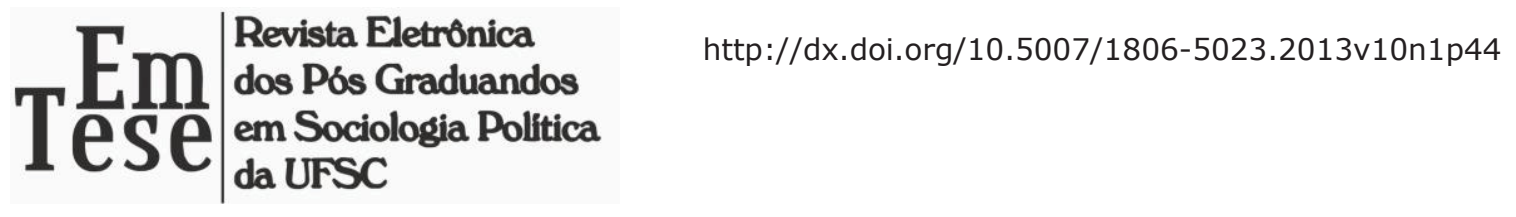

RESUMO: A proposta central deste artigo é explorar as diferenças fundamentais entre a teoria da ação de Max Weber e Georg Simmel, estas que, apesar de serem frutos de um mesmo período histórico - a modernidade - estatuíram concepções diametralmente opostas acerca da natureza do homem e de sua atividade típica. Enquanto Weber baseia sua teoria da ação no valor genérico da razão, Simmel enxerga a ação como fundamentada pela inesgotabilidade produtiva da vida. Após buscar demonstrar, através de um empreendimento arqueológico, os princípios-guia sobre os quais se sustentam as duas teorias da ação, estabelecer-se-á uma confrontação entre elas, a fim de sopesar suas divergências fundamentais. Por fim, valendo-se da reflexão de Alfred Schütz, buscaremos demonstrar que a reflexão de Simmel opera num nível mais originário e, portanto, é mais radical do que a proposta de Weber.

PALAVRAS-CHAVE: Ação. Vida. Razão, Georg Simmel. Max Weber.

\begin{abstract}
The purpose of this article is to explore the fundamental differences between the action theory of Max Weber and Georg Simmel, those who, despite being the product of the same historical period - the modernity - drew opposing views about the nature of man and his typical activity. While Weber bases his theory of action on the generic value of reason, Simmel sees the action as based on productivity inexhaustible life. After seeking to demonstrate, through a genealogical project, the guiding principles upon which underlie the two theories of action, we will establish a confrontation between them, in order to weigh their fundamental differences. Finally, using the reflection of Alfred Schütz, we pursue to demonstrate that the Simmel's reflection operates at a more original and therefore is more radical than the Weber's propose.
\end{abstract}

KEY-WORDS: Action, life, reason, Georg Simmel, Max Weber.

Recebido em: 01 de Janeiro de 2013

Aceito para publicação em: 29 de Agosto de 2013 